\title{
Experiments on a Crossflow Heat Exchanger With Tubes of Lenticular Shape
}

California Institute of Technology, Pasadena, Calif
Measurements of pressure losses and heat transfer rates were made for an unconventional crossflow heat exchanger with tubes of lenticular cross section so spaced to reduce variation in the velocity of the fluid outside the tubes, thus reducing separation and drag. The results of these experiments are reported for various tube spacing and demonstrate that the performance of the lenticular tube heat exchanger is superior to that of conventional circular tubes by 20 percent at Reynolds numbers of 20,000 to 50,000.

\section{Introduction}

One of the major objectives in the design of heat exchangers is the reduction of pressure drop for a given amount of heat transferred. In some applications, for example, the natural draft dry cooling tower, the overall performance is critically dependent on pressure drop. This paper gives the results of an investigation of a method of reducing the pressure drop.

Crossflow tubular heat exchangers have been studied by many investigators, with most of the experiments performed on exchangers made up of tubes of circular cross section in regular arrays. Pierson, Huge, and Grimison [1-3] undertook extensive measurements in 1926 for the Babcock and Wilcox Company on both staggered and inline arrangements with various ratios of pitch to diameter. Correlations of these data with the work of others have been done for heat transfer by Fishenden and Saunders [4] and for pressure loss by Jakob [5]. More recently, Zhukauskas [6] performed many heat transfer experiments with single tubes and banks of cylinders. The effect of the number of rows has been investigated by Kays [7-8].

Tubes of circular cross section cause severe separation and large wakes in turbulent flow normal to the tubes. Such separated flow increases pressure drop more than heat transfer when compared with turbulent flow inside a smooth tube of constant cross section. In the experiments described here, heat exchanger tubes of lenticular cross section were arranged to reduce the area variations presented to the crossflow. In this fashion, the severity of the separation is reduced and the pressure loss decreased.

\section{Performance Criteria}

The cross section of a lenticular tube heat exchanger is depicted in Fig. 1. The cross section of these tubes is formed from two circular arcs joined together. The geometrical arrangement is defined by the chord, $C$, the half thickness, $h$, the spacings, $s_{1}, s_{2}$, and the number of rows, $N$.

By arranging the lenticular tubes with the spacing $s_{1}$ equal to $s_{2}$, the flow area through the heat exchanger is more nearly constant than is possible with tubes of circular cross section. This gives an advantage in that flow through the nearly constant area will have lower accelerations and pressure gradients, and thus, there should be smaller wakes and lower form drag for the lenticular tubes.

\footnotetext{
'Graduate Research Assistant, California Institute of Technology, now Member of the Technical Staff, The Aerospace Corporation, El Segundo, Calif. 90009

Contributed by the Heat Transfer Division for publication in the Journal of Heat Transfer. Manuscript received by the Heat Transfer Division March 1, 1982 .
}

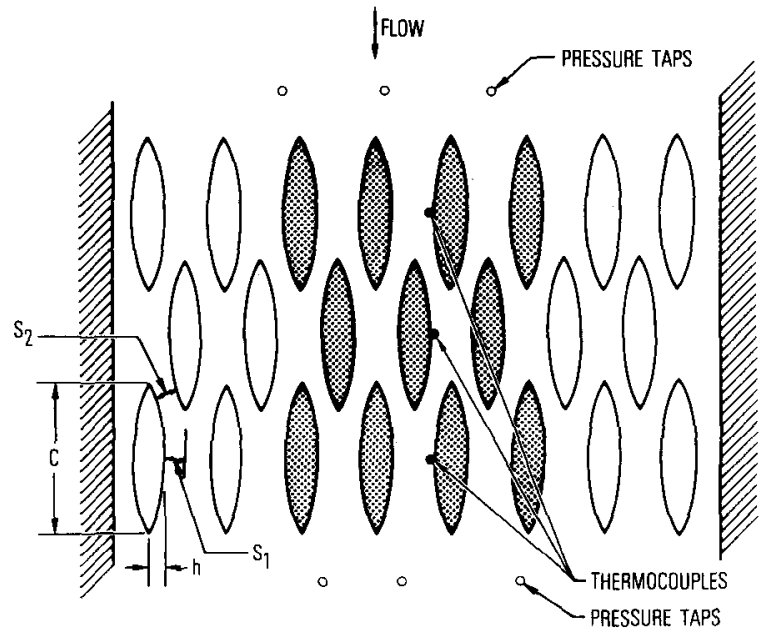

Fig. 1 Schematic diagram of top view of bundle with heated tubes shown in solid

The drag on the outside of a crossflow heat exchanger can be expressed as

$$
A \Delta P=\rho U_{\max }^{2} S C_{f} / 2
$$

The drag is equal to the product of the frontal area of the heat exchanger, $A$, and the pressure difference across it, $\Delta P$. $C_{f}$ is a dimensionless drag coefficient, which is the usual skin friction coefficient if there is no separation. Here $\rho$ is the density of the fluid, $U_{\max }$ the reference velocity based on the velocity through the minimum flow area, and $S$ the wetted surface area.

The heat transfer rate, $\dot{Q}$, can be expressed as

$$
\dot{Q}=\rho C_{p} \Delta T_{w} S C_{h} U_{\max }
$$

where $C_{p}$ is the specific heat at constant pressure for the fluid and $\Delta T_{w}$ is the temperature difference between the fluid and the wall of the heat exchanger. The parameter, $C_{h}$, is the Stanton number. The pumping power, $\dot{W}$, required to drive the fluid across the heat exchanger is given by the product of the drag and the velocity

$$
\dot{W}=A \Delta P U_{\max }
$$

Thus the ratio of pumping power to heat transfer rate is

$$
\dot{W} / \dot{Q}=U_{\max }^{2} /\left(C_{p} \Delta T_{w}\right) \cdot\left(C_{f} / 2 C_{h}\right)
$$

For a forced draft application with a prescribed velocity and temperature difference and a given heat transfer rate, the minimum required pumping power will occur at the minimum value of $C_{f} / 2 C_{h}$.

A natural draft heat exchanger at the base of a cooling 


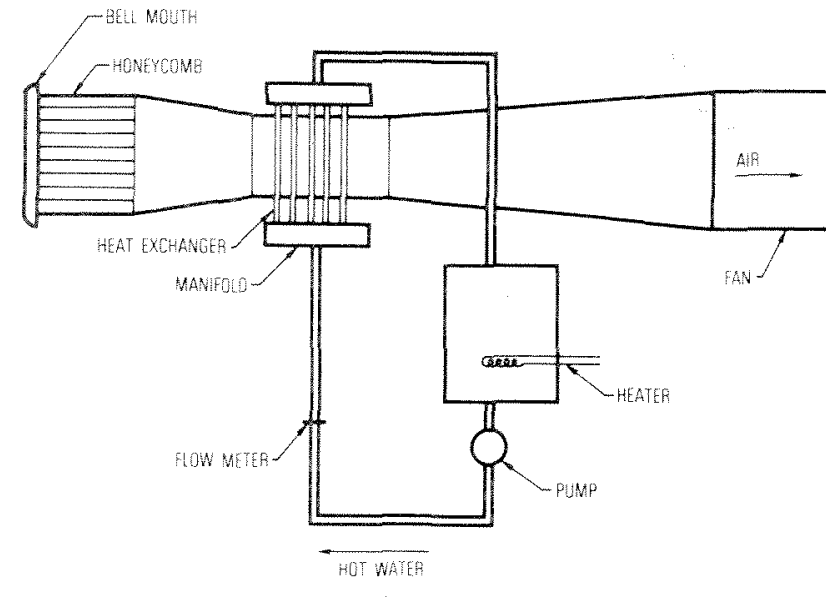

Fig.2 Wind tunnel layout

tower is slightly more complicated, but it can be shown [9] that for the optimum value of $S / A$

$$
\dot{Q} / A=0.5690[\gamma /(\gamma-1)](g H)^{1 / 2}\left(\Delta T_{w} / T_{o}\right)^{3 / 2} P_{o}\left(C_{f} / 2 C_{h}\right)^{-2}
$$

where $g$ is the acceleration due to gravity, $H$ is the height of the tower, $T_{0}$ and $P_{0}$ are ambient absolute temperature and pressure, and $\gamma$ is the ratio of specific heats of air. For given values of these parameters with this configuration, the heat transfer per unit frontal area is a maximum for the minimum value of $C_{f} / 2 C_{h}$.

In general, the ratio of the coefficients $C_{f} / 2 C_{k}$ is a function of geometry, Prandil number, and Reynolds number. For turbulent flow of a gas inside a smooth tube, Reynolds analogy leads to $C_{f} / 2 C_{h} \cong 1$. Wall roughness or any other geometry that causes flow separation increases drag more than heat transfer giving $C_{f} / 2 C_{h}>1$.

The choice of design of a heat exchanger is strongly dependent on the system of which it is a part. Here, the parameter $C_{f} / 2 C_{h}$ will be used to compare heat exchangers of different geometries, a measure of both pumping requirements and heat transfer.

\section{Experimental Apparatus}

A small wind tunnel, as shown in Fig. 2, was built to carry out these experiments. The tunnel was made of plywood and was about $6.1 \mathrm{~m}$ in length. It was an open-circuit tunnel with air drawn through it by a $5.6 \mathrm{~kW}$ fan. A deep aluminum honeycomb at the entrance smoothed the flow and reduced or climinated temperature fluctuations with time constant less than about $4.5 \mathrm{~s}$. The working section measured $0.23 \mathrm{~m}$ high by $0.41-\mathrm{m}$ wide. The maximum velocity through the empty tunnel was about $25 \mathrm{~m} / \mathrm{s}$.

Water was heated to temperatures of 70 to $90^{\circ} \mathrm{C}$ in a 55 -gal stainless steel drum by a $5-\mathrm{kW}$ electric resistance heater and was thoroughly stirred before being pumped upward into a manifold which distributed the hot water through flexible hoses to the heat exchanger tubes. After passing through the working section, the water was collected by an upper manifold and returned to the heater tank to be recycled. The water mass flow rate was determined by an orifice flow meter located upstream of the first manifold. Iron-constantan thermocouples of small diameter, inserted into both manifolds and referenced against each other, measured the temperature drop in the water as it flowed through the manifolds, connecting plastic tubes, and heat exchanger tubes.

Similar thermocouples were laid into shallow grooves cut along the half-chord and running the length of the heat exchanger tubes with their junctions at the midpoint and referenced to a total temperature probe upstream of the tube bank. These gave the difference between the tube wall temperature and the temperature of the undisturbed air.

The static pressure drop across the heat exchanger was found by the averaged differential between three upstream static pressure taps in the floor of the tunnel and three downstream static pressure taps. There were also provisions for inserting a total temperature probe and a pitot probe into the tunnel at a number of locations upstream and downstream of the heat exchanger to make surveys across the width of the tunnel.

The lenticular tubes were constructed of segments cut from a brass pipe of circular cross section. The outside chord was $51 \mathrm{~mm}$, the outside half-thickness was $6.4 \mathrm{~mm}$, and the wall $3.2-\mathrm{mm}$ thick. Since these tubes were expensive to manufacture, and since there was a limited capacity of heated water for a large number of tubes, only the middle tubes were "active" with hot water flowing through them. The rest were unheated, "passive" tubes made of wood as shown in Fig. 1. This was felt to be an acceptable procedure as long as the temperature profile had a steep gradient downstream of the boundary between active and passive tubes, as was confirmed in the experiments. The wetted surface of all the tubes was used for the calculation of $C_{f} / 2$; the surface area of the heated tubes was used for $C_{h}$.

Estimates of experimental uncertainty indicated that the temperature measurements were accurate to $\pm 0.24 \mathrm{~K}$. The accuracy of the pressure drop across the heat exchanger was $\pm 24.0 \mathrm{~Pa}$. The velocity through the tunnel was known to $\pm 0.4 \mathrm{~m} / \mathrm{s}$. A check on the heat transfer rate was done by making velocity and temperature surveys across the tunnel

\section{Nomenclature}

$$
\begin{aligned}
A= & \text { frontal area, } \mathrm{m}^{2} \\
A_{\mathrm{min}}= & \text { minimum free area, } \mathrm{m}^{2} \\
C= & \text { chord of lenticular tube, } \mathrm{m} \\
C_{f} / 2= & \text { drag coefficient, dimen- } \\
& \text { sionless } \\
C_{h}= & \text { Stanton number }(\text { the } \\
& \text { Colbum factor } \left.=C_{h} \operatorname{Pr}^{2 / 3}\right), \\
& \text { dimerisionless }
\end{aligned}
$$

\footnotetext{
Relationship between nomenclature of this paper and Kays and London [10]:

$\begin{array}{ll}\text { Ruth } & \text { Kays-London } \\ C_{j} / 2 & f / 2 \sigma \\ C_{h} & N_{\mathrm{Si}} \\ \mathrm{Re} & N_{R} 2 s_{1} /\left(4 r_{h}\right)\end{array}$
}

$$
\begin{aligned}
s_{1}= & \text { distance from side of len- } \\
& \text { ticular tube to centerline of } \\
& \text { adjacent tube in next row, } \mathrm{m} \\
s_{2}= & \text { minimum distance between } \\
& \text { lenticular tube and adjacent } \\
& \text { tube in next row, } \mathrm{m} \\
\Delta T= & \text { temperature difference } \\
& \text { between fluid and wall, } \mathrm{K} \\
U_{\mathrm{max}}= & \text { nominal maximum velocity } \\
& \text { calculated from minimum } \\
& \text { area, m/s } \\
\dot{W}= & \text { pumping power, } \mathrm{W} \\
\gamma= & \text { ratio of specific heats, } \\
& \text { dimensionless } \\
\nu= & \text { kinematic viscosity, } \mathrm{m}^{2} / \mathrm{s} \\
\rho= & \text { nuid density, } \mathrm{kg} / \mathrm{m}^{3}
\end{aligned}
$$




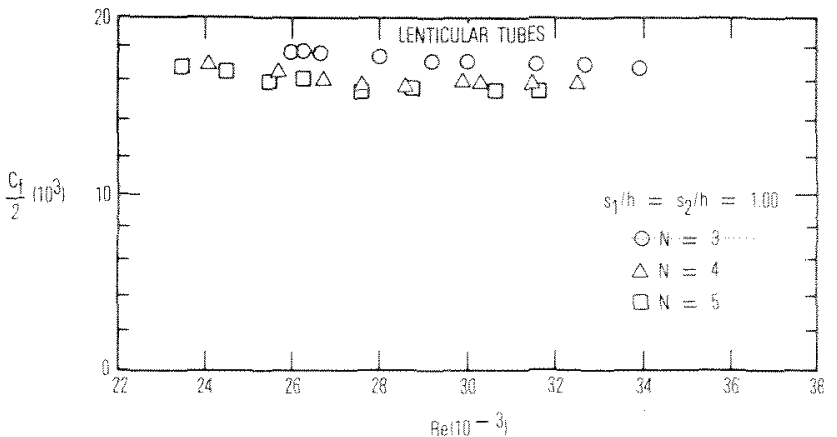

Fig. $3 \quad C_{f}$ versus Re for $s_{1}=s_{2}=\hbar$

midplane both up and downstream of the heat exchanger and numerically integrating the results. The difference in the integrated energy flux calculated from these surveys should equal the heat transfer rate of the exchanger. However, since these surveys did not include the boundary layers on the upper and lower tunnel surfaces, some discrepancies occurred. Vertical surveys showed that the temperature difference across the heat exchanger was higher in the boundary layer than in the midplane. Generally, the mass flow rate was 10 percent higher and the heat transfer rate 5 percent lower for the integrated measurements than for the direct measurements. Given that the survey results did not take the boundary layers into account, this was considered a good check on the heat transfer measurements.

\section{Results and Discussion}

Three spacings of lenticular tubes were investigated: $s_{1} / h=$ $s_{2} / h=1.00\left(s_{t} / h=2, s_{1} / h=5.89\right), s_{1} / h=s_{2} / h=3.50$ $\left(s_{l} / h=4.50, s_{1} / h=6.30\right)$, and the geometric mean of the two: $s_{1} / h=s_{2} / h=1.91\left(s_{t} / h=2.91, s_{l} / h=6.05\right) .^{3}$ These spacings were selected to give a range of tube packing from densely packed to a more open spacing. Tests were run with 3 , 4 , and 5 rows for each spacing.

The results of the experiments are plotted with the parameters $C_{h}, C_{f} / 2$, and $C_{f} / 2 C_{h}$ as functions of Reynolds number, Re. The reference velocity $U_{\max }$ is based on the nominal maximum velocity calculated from the minimum area. The Reynolds number is based upon $U_{\text {max }}$ and the minimum spacing between the tubes.

$$
\mathrm{Re}=U_{\max } 2 s_{1} / v
$$

where $v$ the kinematic viscosity for air.

The first set of experiments was carried out for the configuration with $s_{1}=s_{2}=h$. In Fig. $3, C_{f} / 2$ is plotted against Re. As can be seen, there is a slight decrease in $C_{f} / 2$ with increasing number of rows. The plot of $C_{h}$ versus Re in Fig. 4 shows some increase with the addition of more rows. Thus, the ratio of $C_{f} / 2 C_{h}$ in Fig. 5 shows an improvement in performance with the addition of more rows. The improvement from 4 to 5 rows is somewhat less than the improvement from 3 to 4 rows.

In comparison, the data for circular tubes $[7-8]$ show that $C_{f} / 2$ is nearly independent of the number of rows and that $C_{i n}$ increases with each additional row until a constant value is reached for 10 or more rows. At similar Reynolds numbers, heat exchangers made up of inline arrangements of circular cylinders have values of $C / 2 C_{n}$ of 12 or less, depending on the number of rows and spacing of the tubes. This will be discussed more fully in the section following.

Tufts placed on the roof and floor of the test section just downstream of the last row of lenticular tubes revealed the

\footnotetext{
${ }^{3}$ The ratio of minimum free fow area to fronal area for the three test geomeries was $0.50,0.78$, and 0.66
}

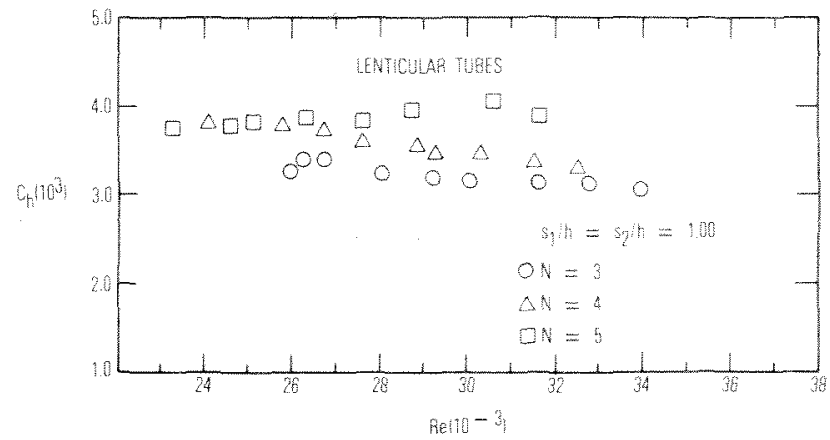

Fig. $4 C_{h}$ versus Re for $s_{1}=s_{2}=h$

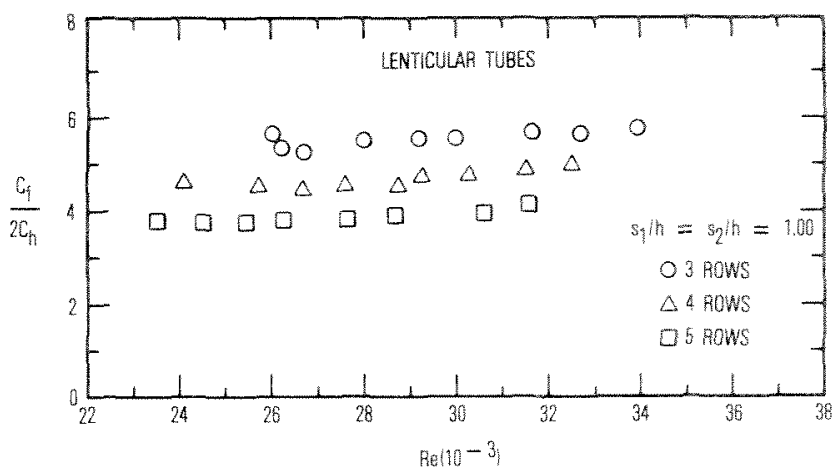

Fig. $5 \quad C_{f} / 2 C_{h}$ versus Re for $s_{1}=s_{2}=h$
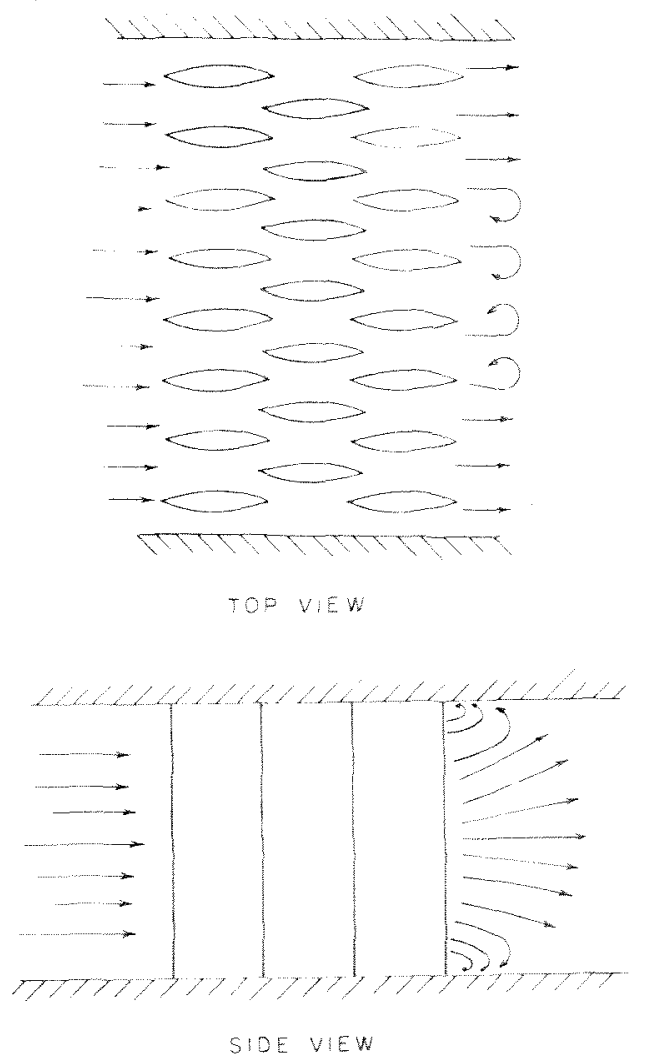

Fig.6 separation bubble

existence of a region of recirculating flow at the center of the tunnel. Velocity surveys showed this region to be a "bubble" of separated flow $10-1015-\mathrm{cm}$ wide and $1-$ to $2-\mathrm{cm}$ high just after the last row but apparently not extending upstream into the tube bank (Fig. 6). 
An explanation of this phenomenon is that the crosssectional area of the channels between the tubes diverges rapidly after the midpoint of the last row. The consequent deceleration, if large enough, tends to cause separation of the boundary layer in the corners of the tube surfaces and tunnel walls. In effect, this last row of tubes forms an array of diffusers. Separation occurs for the closer spacings, since these have the greater diffuser angles. As to why the separation occurs only in the middle of the tunnel, an analogy might be made with the case of a stalled three-dimensional wing or of rotating stall in a compressor. There separation occurs in patches, relieving conditions along the rest of the wing or blades where the flow remains attached.

The most closely spaced arrangement, $s_{1}=s_{2}=h$, had a separation bubble for all numbers of rows tested; whereas, the wide spacing $s_{1}=s_{2}=3.5 \mathrm{~h}$ did not have a separated region for any case. For the intermediate spacing, $s_{1}=s_{2}=1.91 \mathrm{~h}$, there was no separation for 3 and 4 rows, but for 5 rows the separation bubble appeared. Best performance was for this last case, i.e., $s_{1}=s_{2}=1.91 \mathrm{~h}$ and 5 rows. In all cases, $C_{f} / 2 C_{h}$ decreased with increasing number of rows. These results are presented in detail in Table 1 and discussed in [9].

Some experiments were made at low Reynolds numbers using the configuration that gave the best performance at higher Reynolds numbers, $s_{1}=s_{2}=1.91 \mathrm{~h}$ and 5 rows. To achieve low Reynolds numbers, an orifice plate was installed at the diffuser exit to reduce the flow through the fan. By changing the size of the hole in the orifice plate in combination with the normal velocity control, a range of Reynolds number was explored.

Figure 7 is a plot of $C_{f} / 2$ as a function of Re. A simple power relationship is drawn through the points. The plot of $C_{h}$ versus $R e$ is shown in Fig. 8 again with a simple power curve fit. Both $C_{f} / 2$ and $C_{h}$ are rapidly decreasing functions with increasing Reynolds number near the origin. Figure 9 shows that $C_{f} / 2 C_{h}$ is an increasing function of the Reynolds number.

\section{Comparison of Heat Exchanger Configuration}

The characteristics desired in a heat exchanger depend strongly on the particular application. In this investigation, the ratio $C_{f} / 2 C_{h}$ has been used as a figure of merit to com- pare heat exchangers of the same type. However, this ratio is dependent on the geometry and Reynolds number, which in turn depend on the application. Hence, it is not possible in general to find a single criterion for comparing different types of heat exchangers and pronounce one superior to the other. Here no attempt will be made to select one type of heat ex-

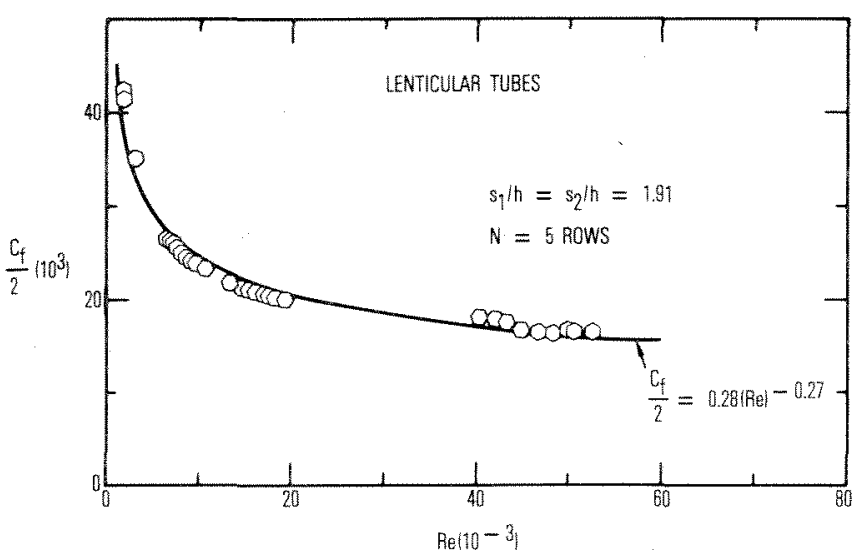

Fig. $7 \quad C_{f} / 2$ versus Re extended Reynolds number for $s_{1}=s_{2}=1.91$ $h, N=5$

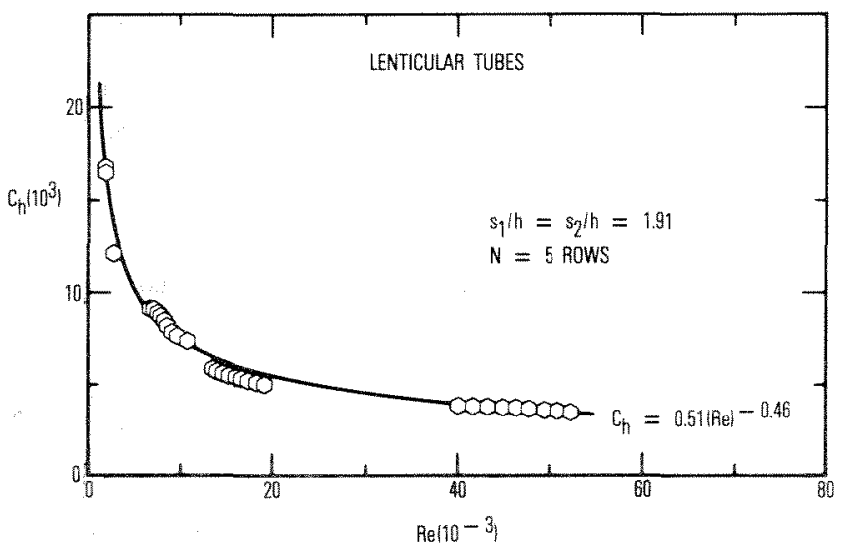

Fig. $8 c_{h}$ versus Re extended Reynolds number for $s_{1}=s_{2}=1.91 \mathrm{~h}$ $N=5$

Table 1 Experimental data for lenticular heat exchanger

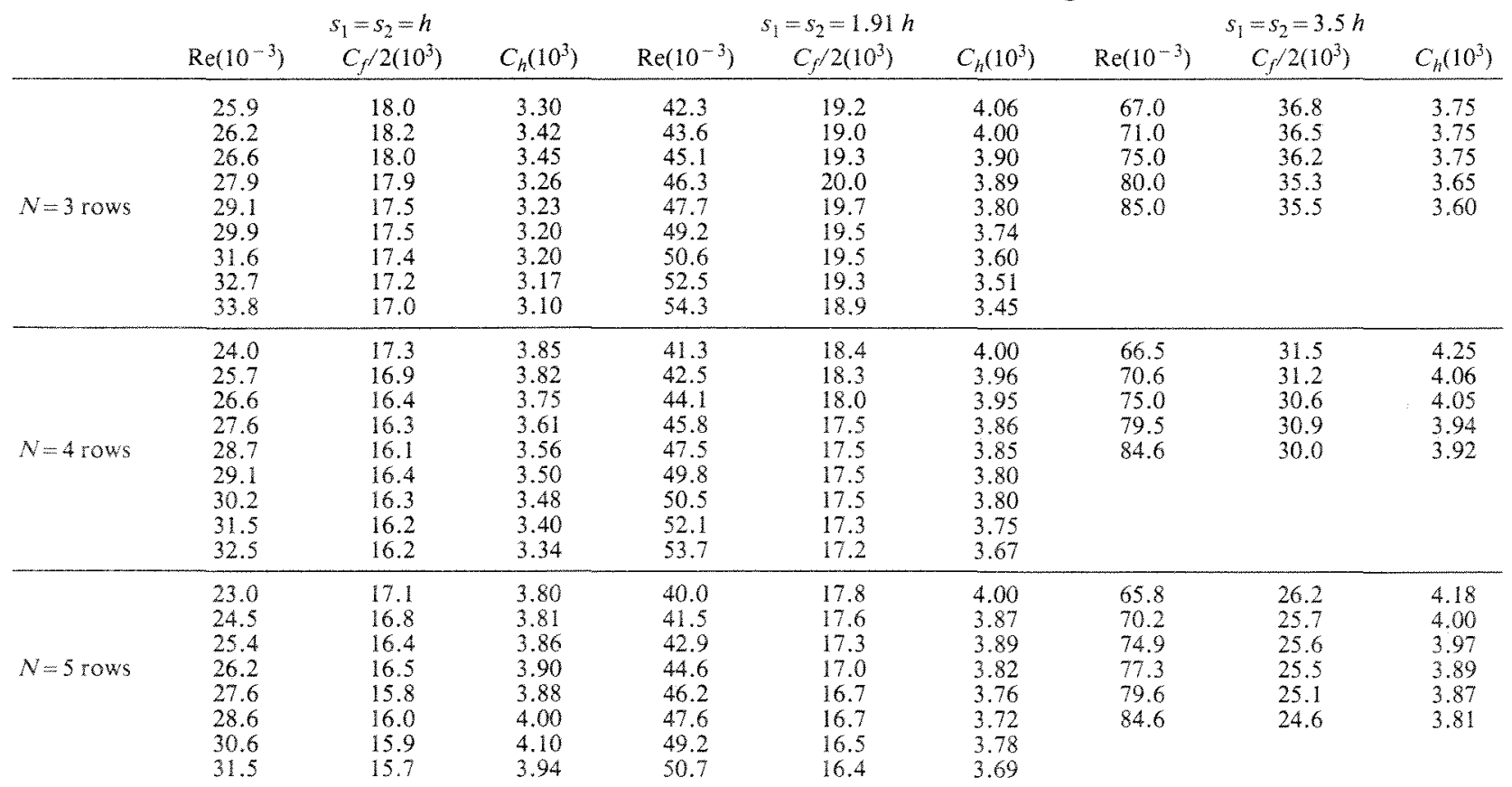




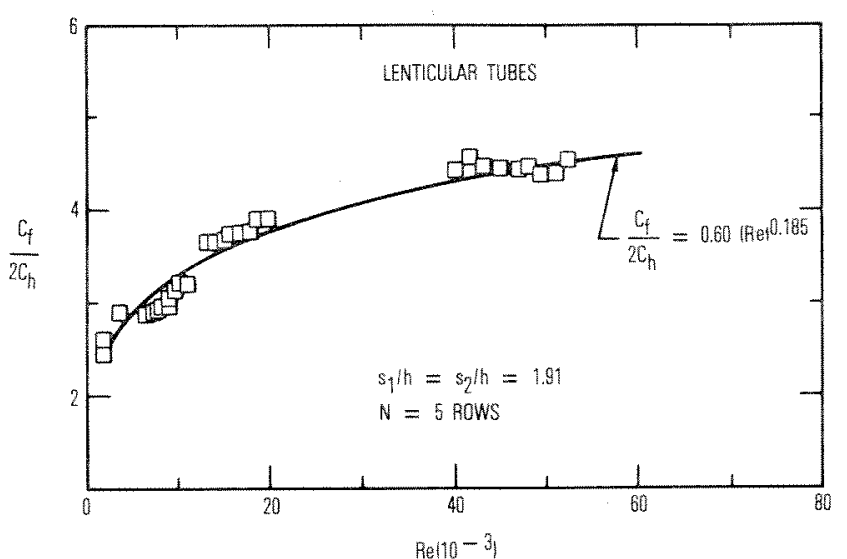

Fig. $9 \quad C_{f} / 2 C_{h}$ versus Re extended Reynotds number for $s_{1}=s_{2}=$ $1.91 h, N=5$

changer over another, but, information on the arrangements investigated will be compared with the available data for more conventional types of similar size.

Calculations based on the data $[1,6]$ for circular cylinders in staggered and inline arrangements show that staggered layouts have high Stanton numbers, but also very high pressure loss coefficients, so that the ratio of $C_{f} / 2 C_{h}$ turns out to be lower for inline arrangements, although the latter have lower values of $C_{h}$. For this reason, the inline arrangement was used as a standard for comparison with the lenticular shaped tubes.

Figure 10 is a comparison of these data with the results for lenticular tube heat exchanger. The hexagons represent the experiment described previously for $s_{1}=s_{2}=1.91 \mathrm{~h}$ and 5 rows. This was the arrangement with the lowest values of $C_{f} / 2 C_{h}$. The ratio of frontal area to minimum free area, $A / A_{\min }$, was 1.52 and the value of $S / A$ was 14.3

For comparison an inline bank of circular tubes with a transverse spacing of $s_{i} / d=3$, a longitudinal spacing $s_{1} / d=$ 1.25 , and corrected for 5 rows was picked since it has the lowest values of $C_{f} / 2 C_{h}$ appearing in Pierson's data. For this configuration, $S / A=5.24, A / A_{\min }=1.50$.

At the higher Reynolds numbers, the lenticular tubes are about 20 percent better than the circular tubes. The lenticular tubes have higher surface area/frontal area and are much more compact.

Besides the inline tube data of Pierson and Zhukauskas, Fig. 10 includes data from Kays and London [10] for a staggered arrangement of oval tubes made of flattened circular cylinders. ${ }^{4}$ This arrangement is similar to the lenticular tuhe heat exchanger but has larger variations of nominal velocity in the tube bank. Information is available only for one spacing with $A / A_{\min }=2.59$ and a surface area per uni volume of $354 \mathrm{~m}^{2} / \mathrm{m}^{3}$. The tubes were $8-\mathrm{mm}$ long, $3.2-\mathrm{mm}$ thick and had a transverse spacing of $5.6 \mathrm{~mm}$ and longitudinal spacing of $8.7 \mathrm{~mm}$.

For reference, the plot for turbulent flow of air inside a circular pipe is shown. This plot is simply the result of Reynolds analogy using the mean velocity as a reference of $C_{j} / 2 C_{h}=\operatorname{Pr}=0.7$ for air

\section{Conclusion}

The purpose of these experiments was to investigate the performance of an unconventional crossflow heat exchanger configuration to determine if it might lead to a decrease in the pressure loss of the flow through the heat exchanger for a

\footnotetext{
${ }^{4}$ All the data of Pierson [1], Zhukauskas [6], and Kays and London [10] have been recomputed based on 25 , (the minimum spacing between twbes) as the characteristic length so conform with the lenteurar tube data.
}

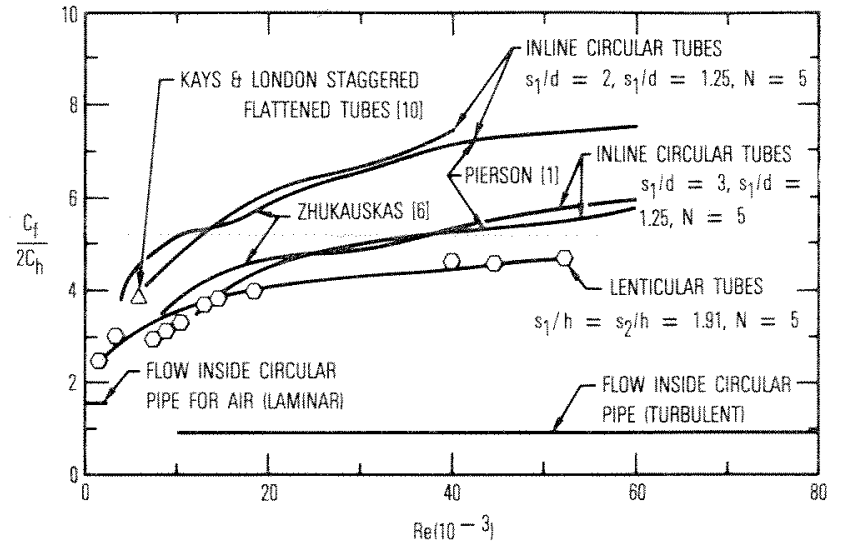

Fig. 10 Comparison of different types of heas exchangers

given heat transfer rate. As stated earlier, it is difficult to compare different types of heat exchangers without considering their intended applications. In this investigation, the ratio of friction coefficient to heat transfer coefficient in the form $C_{f} / 2 C_{h}$ was chosen as a figure of merit to be used in comparing different geometries of both forced and natural draft heat exchangers, since it takes into account both pressure loss and heat transfer rate.

The experiments considered lenticular shaped tubes spaced so that the flow area between them was nearly constant through the tube bank and gave lower values of $C_{f} / 2 C_{h}$ than conventional heat exchangers with tubes of circular cross section, especially for $\operatorname{Re}=20,000$ to 50,000 . The better performance of the lenticular tubes compared with circular tubes must be balanced against the disadvantage of a shape that may be more difficult to manufacture and to install in a device (i.e., it is more difficult to design headers for odd shaped tubes). Also, the lenticular shape is not as good a pressure vessel as a circular tube.

\section{Acknowledgment}

This investigation was supported by the U.S. Department of Energy under Contract EX 76-G-OJ-1305 with the California Institute of Technology. The author wishes to express his thanks for this support and to Professor W. D. Rannie, who suggested the investigation and gave advice during its execution.

\section{References}

1 Pierson, O., "Experimental Investigation of Intuence of Tube Amangement on Convection Heat Transfer and Flow Resistance in Crossflow of Gases Over Tube Banks," ASME Transactions, Vol. 59, 1937, pp. 563-572.

2 Huge, E., "Experimental Investigation of Effects of Equipment Size of Convection Heat Transfer and Flow Resistance in Crossflow of Gases Over Tube Banks," ASME Transactions, Vol. 59, 1937, pp. 573-582.

3 Grimison, E., "Correlation and Utilization of New Data on Flow Resistance and Heat Transfer for Crossflow of Gases Over Tube Banks," ASME Transactions, Vol. 59, 1937, pp. 583-594.

4 Fishenden, M., and Saunders, O., An Introduction to Heat Transfer. Clarendon Press, Oxford, 1950 , pp. 132-145.

5 Jakob, M., "Heat Transfer and Flow Resistance in Crossflow of Gases Over Tube Banks," ASME Transactions, Vol. 60, 1938, pp. 384-380.

6 Zhukauskas, A., Heat Transfer in Banks of Tubes in Crossflow of Flizid, Mintis, Vinius, Lithuania, 1968.

7 Kays, W., and Lo, R., "Basic Heat Transfer and Flow Friction Design Data for Gas Flow Nomal to Banks of Staggered Tubes--Use of a Transient Technque," TR No. 15, Mechanical Engineering Department, Stanford University, 1952

8 Kays, W., "Baste Heat Transfer and Flow Friction Design Data for Gas Flow Normal to Banks of In-line Circular Tubes-Use of a Transient Technique," TR No. 21, Mechanical Engineering Deparment, Stanford University, 1954 .

9 Ruth, E., "Experiments With Unconventional Crossflow Heat Exchangers," PhD thesis, Cahorma Instiute of Technology, 1981.

10 Kays, $w$, and London, A., Compact Heat Exchangers, McGraw-Hill Book Company, New York. 1964, p. 165 